\title{
Assessment of Carbohydrate Count Method Knowledge Levels and Insulin Types of Individuals with Type 1 DM
}

\author{
Muge Arslan \\ Istanbul Aydin University, Faculty of Health Sciences, Nutrition and Dietetics Department
}

Correspondence Author: Muge Arslan

E-mail: dyt_muge@hotmail.com

Received: $08.10 .2019 \quad$ Accepted: 6.11.2019

\begin{abstract}
Objectives: The purpose of this research is to evaluate the knowledge status of carbohydrate $(\mathrm{CHO})$ counting method and to examine the insulin types and doses of adult individuals with Type 1 diabetes mellitus (T1DM) who applied CHO count.

Methods: This is a descriptive study. The working group of this study consisted of 118 patients with T1DM who applied CHO counting, aged 18-65 using outpatient treatment in the endocrine outpatient clinics of Antakya Academy Hospital, Private Eastern Mediterranean Hospital and Private Laurel Hospitals in Hatay. In the study, a questionnaire consisting of questions about the participants' introductory information (such as age, gender, weight, height, body mass index (BMI), feeding habits (main meals, snacks, fluid consumption), insulin type and doses and CHO counting information level was applied to the participants.

Results: The mean age of the participants was 35 years, the mean BMl was $24.5 \mathrm{~kg} / \mathrm{m} 2$ the mean duration of diabetes was 13.6 months and the duration of $\mathrm{CHO}$ counting was 22 months. The most frequently used insulin type was rapid-acting insulin with $49.2 \%$. Participants administered the highest amount of insulin overnight and an average of 14.83 units. The most preferred $\mathrm{CHO}$ counting level of the participants was second level with $40.7 \% .57 .6 \%$ of the participants thought that they had information about $\mathrm{CHO}$ counting. Participants have the highest information on CHO counts from dietitians (51.7\%). Participants' most preferred method when performing CHO counting; The portion estimation method with $50.8 \%$. In addition, $68.6 \%$ of the participants stated that they had no difficulty in adjusting insulin dosage by CHO counting method. $67.8 \%$ of the participants thought that $\mathrm{CHO}$ amount was more important than $\mathrm{CHO}$ types. In addition, $44.1 \%$ of the participants who used $\mathrm{CHO}$ counting method had information about CHO containing foods, but they hadn't enough information, and $16.9 \%$ of the participants said that they have no idea. Conclusions: Participants were most likely to use overnight and rapid-long-acting insulin, and their preferred method of $\mathrm{CHO}$ counting was second level. The majority of participants had knowledge of $\mathrm{CHO}$ counting, but their knowledge were insufficient. In addition, the majority of participants didn't have difficulty adjusting insulin dosage by $\mathrm{CHO}$ counting method.

Keywords: T1DM, insulin, carbohydrate counting, nutrition, knowledge
\end{abstract}

\section{INTRODUCTION}

Type 1 diabetes mellitus (T1DM) is one of the most demanding medical illnesses, and according to the International Diabetes Federation, "diabetes is one of the largest global health emergencies of the 21st century $(1,2)$. According to the 2013 data of the International Diabetes Federation, it has been determined that there are 382 million people in the world. This number is expected to rise to 592 million by 2035 (3). One of the main therapeutic objectives to prevent or delay long-term diabetes complications in T1DM is the achievement and maintenance of near-normal glycemic control (1). It is not enough to rely solely on insulin treatment, and nutrition patterns play an important role in regulating blood glucose $(4,5)$. Treatment of T1DM includes insulin therapy, monitoring of nutrition, exercise and glycemic control (6). Carbohydrates ( $\mathrm{CHO}$ ) has the most important effect on increasing postprandial blood glucose levels in T1DM nutrition control and there is a linear correlation between the amount of $\mathrm{CHO}$ consumed and the mealtime and insulin döşe $(7,8)$. Carbohydrates which are both simple and complex affects postprandial blood glucose levels greatly compared to proteins and fats (9). The $\mathrm{CHO}$ counting method has been used in the treatment of diabetes since the 1920s (10). CHO counting is a meal planning approach which focus on $\mathrm{CHO}$ as the primary nutrient affecting postprandial glycemic response used by people with diabetes $(4,5)$. The $\mathrm{CHO}$ counting method provides improved glycemic control and flexibility in food choices. Dietary recommendations of the American Diabetes Association recommend the use of $\mathrm{CHO}$ counting to improve glycemic control (11). In the study by Laurenzi et al.(12) a decrease in $\mathrm{HbA1C}$ was observed in patients who performed $\mathrm{CHO}$ counting compared to patients who calculated other primal insulin döşe. A recent meta-analysis showed that 24 of the 27 studies included had a reduction in $\mathrm{A} 1 \mathrm{C}(0.2-1.2 \%)$ after starting the $\mathrm{CHO}$ counting (13). In a study by Koontz et al.(14) young people with diabetes used $\mathrm{CHO}$ counting, evaluated insulin doses and $\mathrm{HbA} 1 \mathrm{C}$ levels were found to be low. Portion control is important in $\mathrm{CHO}$ counting. It is stated that changing lists, practical kitchen measurements (cups, spoons, bowls, plates of various sizes), hand measurements (punch, palm, soft drink box), labels, kitchen scale and books showing $\mathrm{CHO}$ contents 
of foods can be used for portion control (15). CHO counting methods are performed in 3 ways; Counting the grams of carbohydrates, counting the $\mathrm{CHO}$ option(15 $\mathrm{g}$ CHO exchange lists), counting portions of foods containing $\mathrm{CHO}$. While there is no international consensus as to which method is best, American Dietetic Association (ADA) and International Society for Pediatric and Adolescent Diabetes (ISPAD) have reported that it is necessary to assess the amount of $\mathrm{CHO}$ (weight, change lists, portion) (16).

In the light of all this information, the $\mathrm{CHO}$ counting method not only contributes to the improvement of glucose values and adjustment of insulin doses of diabetic individuals, but also provides more flexible nutrition options for these individuals providing a better quality of life and prevention of acute and chronic complications related to diabetes. From this point of view, it is important in countries' health policies in terms of combating diabetes, in terms of presenting the current situation and establishing constructive and corrective health policies. In addition, the increase of healthy individuals is important in terms of decreasing health expenditures and decreasing the presence of more efficient, productive and productive employees in work life and reducing social burden. This study is also an important guiding feature in the future scientific studies.

\section{MATERIALS AND METHODS}

\subsection{Participants and setting}

The study group of this study consisted of 118 patients with T1DM who used $\mathrm{CHO}$ counting method in outpatient clinics of PrivateAntakyaAkademicHospital,PrivateEastMediterranean Hospital and Private Defne Hospitals in Hatay. The criteria for inclusion in the study were T1DM between 18-65 years of age and using $\mathrm{CHO}$ counting method. Data collection process was completed between May-July 2019 immediately after the approval of the ethics committee. According to population and sample number, the results of present study reflected a 0.05 error rate and 0.95 confidence interval.

\subsection{Instruments}

A questionnaire was conducted in order to collect general information (age, gender, body weight, height) about the patients. The questionnaire also included items regarding nutritional habits (main meals, snacks, fluid consumption) and level of knowledge regarding $\mathrm{CHO}$ counting. Three types of $\mathrm{CHO}$ counting have been identified based on increasing levels of complexity.

Level 1: Introducing the concept of $\mathrm{CHO}$ counting, identifying foods that contain $\mathrm{CHO}$, learn the sources of $\mathrm{CHO}$ information (e.g., label reading), counting grams of $\mathrm{CHO}$ in food, and consistent $\mathrm{CHO}$ intake.

Level 2: Defining the relationship between food - blood glucose level and exercise.
Level 3: Able to match the amount of $\mathrm{CHO}$ consumes with the dosage of insülin (22).

The tool comprised of $\mathbf{4 1}$ questions in total and face to face interview method was used by the researcher to complete the questionnaire.

\subsection{Equipment and Calculations}

Body mass index of the patients were calculated based on body weight and height using the general formula $\left(\mathrm{kg} / \mathrm{m}^{2}\right.$, where $\mathrm{kg}$ is a person's weight in kilograms and $\mathrm{m}^{2}$ is their height in metres squared). Body mass index values of patients with T1DM were classified according to the BMI classification of the World Health Organization (17).

\subsection{Data collection}

All relevant information regarding the study was provided to the participants and questionnaires were directed to them only after their voluntary approval signature on the consent forms.

\subsection{Ethical aspects of the study}

The study was applied after the permission of Bahçeşehir University Scientific Research and Publication Ethics Committee dated 08.05.2019 and numbered 2019/05. This study was conducted in accordance with the Helsinki Declaration Principles. An application was submitted to the directors of the hospitals where the data were collected with information on the purpose and content of the study, and written informed consent was obtained. The patients that comprised the study sample were informed of the purpose of the study, its benefits and their roles in the study. Participants were informed of the voluntary nature of their participation in the study, and written and verbal consents were obtained. Before data collection began, the patients were informed that they could decline to participate in the study at any stage.

\subsection{Statistical analysis}

The obtained data was analysed using SPSS 21.0 statistical package program. Frequency, percentage, arithmetic means, standard deviation, min, max. values were calculated. Independent simple t test, Annova (one-way analysis of variance) and Pearson correlation tests were used to analyze the parametric data. Mann-Whitney $U$ test, Kruskal-Wallis variance analysis and Spearman correlation analysis tests were used for the analysis of the non-parametric data.

\section{RESULTS}

On evaluating the demographic characteristics of adult individuals with T1DM performing $\mathrm{CHO}$ counting, 118 patients with Type $1 \mathrm{DM}$ participated in the study. $\% 61.0$ of the participants were woman and $\% 39.0$ were man. The mean age of the subjects with T1DM was 35 years, the mean BMI was $24.5 \mathrm{~kg} / \mathrm{m}^{2}$, the mean duration of diabetes was 
13.6 years, and the mean of duration of $\mathrm{CHO}$ counting was 22.4 months. (Table 1)

Table 1. Demographic characteristics of adult individuals with type 1 DM performing $\mathrm{CHO}$ counting

\begin{tabular}{|c|c|c|c|c|}
\hline Characteristics & Minimum & Maximum & Mean & $\begin{array}{ll}\text { Std. Deviation } \\
\text { (SD) }\end{array}$ \\
\hline Age (year) & 18 & 74 & 35,1 & 16,05 \\
\hline Body weight (kg) & 47 & 110 & 69,7 & 13,62 \\
\hline Height $(\mathrm{cm})$ & 150 & 187 & 168,5 & 8,87 \\
\hline $\mathrm{BMI}\left(\mathrm{kg} / \mathrm{m}^{2}\right)$ & 17,7 & 44,0 & 24,5 & 4,22 \\
\hline $\begin{array}{l}\text { Duration of } \\
\text { diabetes (years) }\end{array}$ & 1 & 55 & 13,6 & 10,42 \\
\hline $\begin{array}{l}\text { Duration of } \mathrm{CHO} \\
\text { counting (Months) }\end{array}$ & 1 & 85 & 22,4 & 19,13 \\
\hline Gender & $\mathrm{n}$ & $\%$ & & \\
\hline Woman & 72 & 61,0 & & \\
\hline Man & 46 & 39,0 & & \\
\hline Total & 118 & 100,0 & & \\
\hline \multicolumn{5}{|l|}{ BMI Classification } \\
\hline \multicolumn{3}{|c|}{ BMI } & $\mathbf{n}$ & $\%$ \\
\hline \multicolumn{3}{|c|}{ Underweight $(<18,5)$} & 5 & 4,2 \\
\hline \multicolumn{3}{|c|}{ Normal $(18,50-24,9)$} & 70 & 59,3 \\
\hline \multicolumn{3}{|c|}{ Overweight $(25,0-29,9)$} & 29 & 24,6 \\
\hline \multicolumn{3}{|c|}{ Obese $(30,0+)$} & 14 & 11,9 \\
\hline \multicolumn{3}{|l|}{ Total } & 118 & 100,0 \\
\hline
\end{tabular}

On evaluating the distribution of insulin types and daily insülin used by participants, the most common type of insulin which participants used was $49.2 \%$ rapid-long-acting insülin. Participants administered the highest amount of insulin at night and on average 14.83 units (Table 2).

Table 2. Distribution of insulin types used by participants

\begin{tabular}{|c|c|c|c|c|}
\hline \multicolumn{3}{|c|}{ Insulin types } & $\mathbf{n}$ & $\%$ \\
\hline \multicolumn{3}{|c|}{ Rapid acting } & 36 & 30,5 \\
\hline \multicolumn{3}{|c|}{ Rapid medium acting } & 6 & 5,1 \\
\hline \multicolumn{3}{|c|}{ Rapid long lasting or rapid-long-acting } & 58 & 49,2 \\
\hline \multicolumn{3}{|c|}{ Short acting } & 3 & 2,5 \\
\hline \multicolumn{3}{|c|}{ Short slow acting } & 3 & 2,5 \\
\hline \multicolumn{3}{|c|}{ Long acting } & 6 & 5,2 \\
\hline \multicolumn{3}{|l|}{ Slow acting } & 3 & 2,5 \\
\hline \multicolumn{3}{|c|}{ Slow long acting } & 3 & 2,5 \\
\hline \multicolumn{3}{|c|}{ Total } & 118 & 100,0 \\
\hline \multicolumn{5}{|c|}{ Daily insulin usage doses of the participants } \\
\hline Time & Minimum & Maximum & Mean & Std. Deviation \\
\hline Morning & 2 & \begin{tabular}{|l|}
60 \\
\end{tabular} & 13,75 & 8,40 \\
\hline Afternoon & 0 & 48 & 10,02 & 7,13 \\
\hline Evening & 0 & 50 & 12,74 & 9,43 \\
\hline Night & 0 & 48 & 14,83 & 11,41 \\
\hline
\end{tabular}

On evaluating the $\mathrm{CHO}$ counting levels, having sufficient information about $\mathrm{CHO}$ counting and information sources of $\mathrm{CHO}$ counting method, the most preferred $\mathrm{CHO}$ counting level of the participants was the 2 nd level with $40.7 \%$. $57.6 \%$ of the participants thought that they had information about $\mathrm{CHO}$ counting. Participants had access to information about CHO counting from dietitians with $51.7 \%$ (Table 3 ).

Table 3. $\mathrm{CHO}$ counting levels, having sufficient information about $\mathrm{CHO}$ counting and information sources of $\mathrm{CHO}$ counting method

\begin{tabular}{|l|c|c|}
\hline CHO Counting levels & $\mathbf{n}$ & $\%$ \\
\hline 1. Level & 31 & 26,3 \\
\hline 2. Level & 48 & 40,7 \\
\hline 3. Level & 39 & 33,0 \\
\hline Total & $\mathbf{1 1 8}$ & $\mathbf{1 0 0 , 0}$ \\
\hline Having information about CHO counting & $\mathbf{n}$ & $\%$ \\
\hline Yes & 68 & 57,6 \\
\hline No & 50 & 42,4 \\
\hline Total & $\mathbf{1 1 8}$ & $\mathbf{1 0 0 , 0}$ \\
\hline Information sources & $\mathbf{n}$ & $\%$ \\
\hline Media communication devices (tv, radio) & 6 & 5,1 \\
\hline Newspaper & 3 & 2,5 \\
\hline Book & 3 & 2,5 \\
\hline Internet & 5 & 4,3 \\
\hline Doctor & 32 & 27,1 \\
\hline Dietitian & 61 & 51,7 \\
\hline Other health workers & 8 & 6,8 \\
\hline Total & $\mathbf{1 1 8}$ & $\mathbf{1 0 0 , 0}$ \\
\hline
\end{tabular}

Participants' most preferred method when performing $\mathrm{CHO}$ counting was the portion estimation method with $50.8 \%$ and the least preferred method was book with $5.9 \%$. In addition, $68.6 \%$ of the participants stated that they had no difficulty in adjusting insulin dosage by $\mathrm{CHO}$ counting method (Table 4).

Table 4. The methods used by the participants in the application of $\mathrm{CHO}$ counting and difficulty in adjusting insulin dosage by $\mathrm{CHO}$ counting method

\begin{tabular}{|l|c|c|}
\hline Methods & $\mathbf{n}$ & $\mathbf{\%}$ \\
\hline Hand measurements (Zimbabwe) & 12 & 10,2 \\
\hline With precision scales & 25 & 21,2 \\
\hline Reading a book & 7 & 5,9 \\
\hline Portion estimation method & 60 & 50,8 \\
\hline CHO estimation factor method & 14 & 11,9 \\
\hline Total & $\mathbf{1 1 8}$ & $\mathbf{1 0 0 , 0}$ \\
\hline Difficulty adjusting insulin dosage by CHO count method & $\mathbf{n}$ & $\mathbf{\%}$ \\
\hline Yes & 37 & 31,4 \\
\hline No & 81 & 68,6 \\
\hline Total & $\mathbf{1 1 8}$ & $\mathbf{1 0 0 , 0}$ \\
\hline
\end{tabular}


On evaluating the participants' views on the importance of CHO types and $\mathrm{CHO}$ amount and the foods which contained $\mathrm{CHO}, 67.8 \%$ of the participants thought that $\mathrm{CHO}$ amount was more important than $\mathrm{CHO}$ types. In addition, $44.1 \%$ of the participants had information about $\mathrm{CHO}$-containing foods, but it was not enough, $16.9 \%$ of participants said they had no idea (Table 5).

Table 5. Participants' views on the importance of $\mathrm{CHO}$ types and $\mathrm{CHO}$ amount and the foods which contained $\mathrm{CHO}$

\begin{tabular}{|l|c|c|}
\hline CHO & $\mathbf{n}$ & $\mathbf{\%}$ \\
\hline CHO types & 38 & 32,2 \\
\hline CHO amount & 80 & 67,8 \\
\hline Total & $\mathbf{1 1 8}$ & $\mathbf{1 0 0 , 0}$ \\
\hline CHO-containing foods & $\mathbf{n}$ & $\mathbf{\%}$ \\
\hline Yes, I know exactly & 46 & 39,0 \\
\hline I have knowledge, but not enough & 52 & 44,1 \\
\hline No, I have no idea & $\mathbf{2 0}$ & 16,9 \\
\hline Total & $\mathbf{1 1 8}$ & $\mathbf{1 0 0 , 0}$ \\
\hline
\end{tabular}

\section{DISCUSSION}

Type 1 diabetes mellitus is one of the most demanding medical illnesses, and according to the International Diabetes Federation, "diabetes is one of the largest global health emergencies of the 21st century $(1,2)$. In the treatment of T1DM, CHO counting plays a role in achieving glycemic control and also provides more flexible nutrition options for these individuals, providing a better quality of life and prevention of acute and chronic complications related to diabetes $(4,5,13)$.

In this study, The mean age of the subjects with T1DM included in this study was 35 years, the mean BMI was 24.5 $\mathrm{kg} / \mathrm{m}^{2}$, the mean duration of diabetes was 13.6 years and the duration of $\mathrm{CHO}$ counting was 22 months. Similarly, in the study performed by Yıldız (18), the mean age of individuals with T1DM was 30 years, the mean BMI was $23.7 \mathrm{~kg} / \mathrm{m}^{2}$, and the duration of diabetes was 12 years. Similarly, in the study conducted by llkova et al (19). the mean age of the patients with DM was 32 years, the mean BMI was $23.2 \mathrm{~kg}$ $/ \mathrm{m}^{2}$ and the duration of diabetes was 13.9 years. Similarly, in the study conducted by Son et al.(20), the mean age of individuals with T1DM was 29 years and the mean duration of diabetes was 11 years. The normal BMI of individuals with T1DM can be explained by the fact that these individuals pay attention to their insulin-controlled diet.

In this study, the most frequently used insulin type was rapidlong-acting insülin similar to the some other researchers (17, $18,20)$. This can be explained by the fact that individuals with T1DM who performed $\mathrm{CHO}$ counting method are concerned about the sudden rise and fall in insulin and prefer rapidlong-acting insulin to reduce risk. In this study, participants used the most insulin at night. This may be explained by the idea that these individuals would be difficult to maintain insulin control during in nighttime sleep processes.
In this study, the most preferred $\mathrm{CHO}$ counting level of the participants was; Second Level Most of the participants thought that they had information about the $\mathrm{CHO}$ counting. It was observed that most of the participants had access to information about $\mathrm{CHO}$ counting method from dietitians and least information from books and newspapers. similar to the some other researchers $(18,22-23)$. In this situation, individuals with T1DM who perform $\mathrm{CHO}$ counting may want to have access to information from dietitian in order to have detailed information about the $\mathrm{CHO}$ counting and to answer their questions about it.

In this study, the most preferred information source on CHO counting method of the participants was portion estimation method, because they thought this method was easier and approachablethan the other methods, and the least preferred methods are both the book and newspaper. In addition, the majority of the participants stated that they had no difficulty in adjusting insulin dosage by $\mathrm{CHO}$ counting method. Similarly, in the study of O'Gorman et al. (23), the majority of the participants stated that they had no difficulty in adjusting insulin dosage by $\mathrm{CHO}$ counting method. This can be explained by the fact that it is easier to adjust glycemic control by the $\mathrm{CHO}$ counting method, with no difficulty adjusting the insulin dose. In this study, the majority of the participants thought that the amount of $\mathrm{CHO}$ was more important than $\mathrm{CHO}$ types. In addition, the vast majority of the participants in the $\mathrm{CHO}$ counting method, had knowledge of $\mathrm{CHO}$-containing foods, but they had not sufficient information, and a small part of them had no idea. This may be explained by the fact that individuals with T1DM who performed to $\mathrm{CHO}$ counting method had knowledge of other therapeutic treatments (medication, insulin), and had a general knowledge of the $\mathrm{CHO}$ counting method, but lack of detailed information.

\section{CONCLUSION}

The most preferred method of $\mathrm{CHO}$ counting method among individuals with T1DM who performed $\mathrm{CHO}$ counting was second level. Furthermore, these individuals had no difficulty adjusting the insulin dosage by the $\mathrm{CHO}$ counting method. Individuals with T1DM who performed $\mathrm{CHO}$ counting method had information about the $\mathrm{CHO}$ counting but need further information.

\section{Acknowledgement}

The authors would like to thank directors of the hospitals where the data were collected and all of participants.

\section{REFERENCES}

[1] Nathan DM, Genuth S, Lachin J, Cleary P, Crofford O, Davis $M$, Rand $L$, Siebert $C$. The effect of intensive treatment of diabetes on the development and progression of long-term complication in insulin-dependent diabetes mellitus. N Engl J Med 1993; 329: 977-986. 
[2] International Diabetes Federation. IDF Diabetes. 7th Ed Brussels: International Diabetes Federation; 2015.

[3] Guariguata L, Whiting DR, Hambleton I, Beagley J, Linnenkamp $\mathrm{U}$, Shaw JE. Global estimates of diabetes prevalence for 2013 and projections for 2035. Diabetes Res Clin Pract 2014; 137149.

[4] Kawamura T. The importance of $\mathrm{CH}$ counting in the treatment of children with diabetes. Pediatr Diabetes 2007; 8(6):57-62.

[5] Sheard NF, Clark NG, Brand-Miller JC, Franz MJ, Pi-Sunyer FX, Mayer-Davis E, Kulkarni K, Geil P. Dietary carbohydrate (amount and type) in the prevention and management of diabetes: a statement by the American diabetes association. Diabetes Care 2004; 27: 2266-2271.

[6] Çelebi A. Tip 1 Diyabetli çocukların hastalıklarına yönelik tutumları ve etkileyen faktörlerin belirlenmesi. Atatürk Üniversitesi Sağlık Bilimleri Enstitüsü, Çocuk Sağlığı ve Hastalıkları Hemşireliği Anabilim Dalı, Yüksek Lisans Tezi, 2000 (Turkish).

[7] Wolever T, Bolognesi C. Source and amount of carbohydrate affect postprandial glucose and insulin in normal subjects. J Nutr. 1996; 126(11): 2798-2806.

[8] Rabasa-Lhoret R, Garon J, Langelier H, Poisson D, Chiasson JL. Effects of meal carbohydrate content on insulin requirements in type 1 diabetic patients treated intensively with the basalbolus (ultralente-regular) insulin regimen. Diabetes Care 1999; 22(5): 667-673.

[9] Chiesa G, Piscopo MA, Rigamonti A, Azzinari A, Bettini S, Bonfanti R, Viscardi M, Meschi F, Chiumello G. Insulin therapy and carbohydrate counting. Acta Biomed 2005; 76 Suppl 3: 8-44.

[10] Delahanty LM, Halford BN. The role of diet behaviors in achieving improved glycemic control in intensively treated patients in the diabetes control and complications trial. Diabetes Care 1993;16:1453-1458.

[11] Meade LT, Rushton WE. Accuracy of carbohydrate counting in adults. Clin Diabetes 2016; 34(3): 142-147.

[12] Laurenzi A, Bolla AM, Panigoni G, Doria V, Uccellatore A, Peretti E, Saibene A, Galimberti G, Bosi E, Scavini M. Effects of carbohydrate counting on glucose control and quality of life over 24 weeks in adult patients with type 1 diabetes on continuous subcutaneous insulin infusion. Diabetes Care 2011; 34:823-827.
[13] Schmidt S, Schelde B, Norgaard K. Effects of advanced carbohydrate counting in patients with type 2 diabetes: a systematic review. Diabet Med 2014;31:886-896.

[14] Koontz MB, Cuttler L, Palmert MR. Development and validation of a questionnaire to assess carbohydrate and insulin dosing knowledge in youth with type 1 diabetes. Diabetes Care 2010;33:457-462.

[15] Metin S. CHO sayımı yöntemi uygulanan Tip 1 diyabetli çocuk ve adölesanlarda diyete uyumdaki engeller ve metabolik etkileri. Başkent Üniversitesi Sağlık Bilimleri Enstitüsü, Beslenme ve Diyetetik Anabilim Dalı, Doktora Tezi, 2015 (Turkish).

[16] American Diabetes Association Position Statement. Standards and Medical Care in Diabetes. Diabetes Care 2015; 38 (1): 1-99.

[17] World Health Organization. Body Mass Index 2019. Available from: http://www.euro.who.int/en/health-topics/diseaseprevention/nutrition/a-healthy-lifestyle/body-mass-indexbmi.

[18] Yıldız K. Türkiye'deki Yoğun insülin tedavisi alan diyabetli bireylerin karbonhidrat sayımı metodunu kullanım durumlarının HBA1C düzeylerine etkisi. İstanbul Üniversitesi Sağlık Bilimleri Enstitüsü, İçhastalıkları Anabilim Dalı, Yüksek Lisans Tezi, 2018 (Turkish).

[19] Ilkova H, Damci T, Karsidag K, Çömlekçi, A, Ayvaz G. The international diabetes management practices study (IDMPS) Turkey's 5th wave results. Turk J Endocrinol Metab 2016; 20(3): 88-96.

[20] Son O, Efe B, Erenoğlu Son N, Akalin A, Kebapçi N. Investigation on carbohydrate counting method in Type 1 diabetic patients. BioMed Research International 2014; 1-8.

[21] Krebs JD, Strong AP, Cresswell P, Reynolds AN, Hanna A, Haeusler S. A randomised trial of the feasibility of a low carbohydrate diet vs standard carbohydrate counting in adults with type 1 diabetes taking body weight into account. Asia Pac J Clin Nutr 2016;25(1):78-84.

[22] Meade LT, Rushton WE. Accuracy of carbohydrate counting in adults. Clin Diabetes 2016; 34(3): 142-147.

[23] O'Gorman J.R, O'Leary O, Finner N, Quinn A, O'Gorman CS. Knowledge of carbohydrate counting and insulin dose calculations among hospital staff in a regional general paediatrics unit. Springer Plus 2015; 4:727. 